\title{
The Comparative Study of Regional Economic Development in China
}

\author{
Hao Dong', Yingrong Zheng ${ }^{1}$ \\ ${ }^{1}$ Shandong Vocational College of Science and Technology, Weifang, Shandong, 261053
}

Keywords: Regional Economic Development, Comparative Study, Chinese Market

\begin{abstract}
In recent years, China's economy and society have experienced a large degree of growth and development, the industrial structure has been continuously adjusted, the degree of regional economic coordination has been continuously enhanced, and the overall economic quality has also been greatly improved. However, it should be noted that there is still a big difference in the growth of China's regional economy. Capital factors, labor factors, technical factors, institutional factors and other aspects have brought about a certain degree of regional economic growth in China. Specifically, the difference in regional economic growth in China is mainly reflected in the difference in total GDP, the difference in GDP growth rate, and the difference in GDP per capita.
\end{abstract}

\section{Introduction}

Since the 1990s, due to various factors, China's regional economic differences have accelerated and expanded. As the famous economist Lewis said, "Every country has some regions that are richer than other regions. Some regions (not It must be the richest region. It develops faster than other regions... because, first of all, different regions have different growth potentials, some regions have rich mineral resources or water resources, or have good natural ports, and In some areas, resources are extremely poor; secondly, even if all regions start under the same resource conditions, individual regions will gain more concentrated development due to geographical concentration." Therefore, regional economic differences are an important part of regional development research. The difference in China's regional economic development is reflected in the fact that the gap in per capita GDP has expanded. The regional relative gap in China's per capita GDP (GDP) has experienced four stages since the founding of the People's Republic of China. The first phase (19521978). The gap in economic development is constantly expanding. According to the constant prices of provinces, municipalities and autonomous regions in 1978, the relative coefficient of per capita GDP of China's regions was $45.5 \%$ in 1952, and then showed an upward trend, reaching a peak of $97.2 \%$ in 1978. This reflects that the relative gap between China and the country in the early days of the founding of the People's Republic of China has been quite large, and then it has continued to rise. This is because the relative gap between urban and rural comparative labor productivity and the comparative labor productivity of workers and peasants in this period is on the rise. The population and labor cannot move freely between industries, sectors and regions. Although the state adopts a balanced development strategy through the allocation of resources, There is still a trend of widening the relative gap in economic development. The second phase (1979-1991 period). The gap in economic development is shrinking. The relative coefficient of GDP per capita across the country fell to $87.45 \%$ in 1985 and fell to $81.75 \%$ in 1991, a decrease of 15 percentage points from 1980. It should be noted that the relative difference coefficient between the constant price and the current year price is much smaller than the latter. The calculation found that the "convergence coefficient" ( $\beta$ ) calculated according to the nonlinear function was 0.014 during the period from 1978 to 1985 , and was 0.005 during the period 1985-1990, that is, the annual convergence rate of per capita GDP in each region was $1.4 \%$ and $0.5 \%$. During this period, the relative gap between labor productivity in urban and rural areas and between workers and peasants also declined (from 1985 onwards), and there was a large degree of movement and transfer between population and labor in industries, sectors and regions. The relative gap in economic development areas has narrowed. The third phase (1992-1995 period). The gap in economic development has re-emerged, and the development of coastal and inland interiors has "converged", but there has been "polarization" between the two 
regions. First, the relative coefficient of per capita GDP of all regions of the country rose to $88.2 \%$ in 1995, which was 6.45 percentage points higher than that in 1991. Second, the ratio of per capita GDP in the richest and poorest regions increased from 11.6 times in 1991 to 15.1 times in 1995; the ratio of GDP per capita in Guangdong to Guizhou increased from 3.41 times in 1991 to 4.48 in 1995. Times. The fourth stage (1996-2000 period). The economy is advancing in the undulating, income growth rate is slowing down, and the income gap has decreased. However, after 1999, with the deepening of economic restructuring, the number of unemployed people has further increased, and the income gap has expanded. In 1998, the per capita GDP of Guangdong and Fujian reached 1.7 to 3.5 times the per capita GDP of the five provinces in the northwest.

\section{Analysis of the Factors Affecting the Differences of Regional Economic Growth}

There are many factors that cause regional economic growth to differ. There are both large environmental factors outside the region and self-influencing factors within the region. These factors affect each other and interact with each other, resulting in economic growth differences between regions. Specifically, the factors that cause regional economic growth differences are capital, labor, technical, and institutional factors. These factors revolve around the impact of their own management on economic growth.

As an important factor affecting the regional economic growth difference, the capital factor itself has a relatively broad content and concept. In a broad sense, capital elements can include related elements such as human capital, physical capital, and land. Most of the research has been simplified, considering only the impact of capital capital input on the difference in regional economic growth. Material capital input can be divided into two types: working capital and fixed capital. In actual research, it is usually measured by the total capital formation index. The total amount of capital formation can be obtained by accumulating the increase in inventory and the total amount of fixed capital formation. It refers to the sum of the added value of fixed assets and the change in inventory that can be obtained in a certain region within a certain period of time.

Among the factors affecting regional economic growth differences, labor factors are also an important content. For the measurement of labor factors, the employment number is generally used for trade-off and analysis, and the labor factors are studied according to the actual number of laborers invested in the production process. Generally speaking, the abstract: With the continuous acceleration of the process of world economic integration and the continuous improvement of the market economic system, China's economic scale and economic aggregate are increasing. In this context, China's regional economic differences are also becoming more and more prominent. Further strengthen the research on the difference of regional economic growth, and clarify the influence mechanism of each factor, which is of great significance for optimizing inter-regional economic development and realizing the free flow of various production factors between different regions. Based on the regional economic growth differences, this paper analyzes the various influencing factors, focuses on the analysis of the role of various influencing factors, and proposes relevant measures on how to strengthen inter-regional economic development coordination and achieve coordinated economic development. Keywords: regional economy, growth, difference, influencing factors, employment, including on-the-job employees, individual owners, reemployed retirees, rural employees, township and village enterprises, private owners, and other employed people. Through the statistical summarization of the above-mentioned personnel, it is reasonable to express and reflect the actual use of labor resources in a certain period of time.

As an important driving force for contemporary economic and social development, technological factors play a central role in promoting China's economic restructuring and industrial upgrading, and realizing the transformation of economic growth mode. Focusing on the regional economic growth difference research, combined with the characteristics of the technical elements, fully exploiting the characteristics of the technical factors themselves and the extensive content of the content, we can select the input factors of the technical elements, the basic conditions of the aggregation, and the output conditions. select. The first is to select indicators for participation in scientific and technological activities. This indicator mainly refers to those who are engaged in 
scientific research activities and have junior or higher titles or bachelor degree or above. It includes both those who conduct research activities directly, as well as those who provide support and support for related research activities. The second is the research expenditure of the whole society. This is mainly the statistical calculation of the amount of expenditure paid for supporting research expenses in a certain region in a certain year. It includes labor costs, equipment and equipment purchase fees, land use fees, research building construction fees, and project commissioned business fees. The third is the number of patents granted or public. This indicator is mainly used to measure the number of patents or inventions authorized by the State Intellectual Property Office.

\section{Analysis of the influence factors of regional economic growth differences}

In general, the economic growth of each region mainly relies on the input of capital elements in the market. In particular, the analysis of the market economic growth factors in the eastern and western regions of China can be found that among the many growth drivers, capital investment is the most important. Content, most regions are using the substantial investment of capital elements to promote and promote economic growth. At the same time, all regions have also improved and upgraded in terms of the quality of economic growth. This has an important positive effect on the overall economic vitality of China, improving the quality of economic development, and tapping the potential of economic development. On this basis, the level of economic development in each region has also developed to varying degrees. Although the factors for growth in economic development vary from region to region, capital investment is the most important factor. It is the biggest. At the same time, on the basis of the contribution of capital investment factors, the contribution of institutional factors and technical factors is also increasing and increasing. These new situations and changes have all explained to a certain extent that all regions have a greater degree of improvement in the quality of economic growth, and economic growth has made a new leap in quality.

In addition to the different degrees of economic growth in different regions, there is also a big difference in economic growth between the eastern region of China and the central and western regions. The economic gap between them has also shown an increasing trend. In terms of capital factor alone, the eastern region occupies a relatively large proportion, which has become the most important driving factor for economic growth in the eastern region and the most important factor leading to the economic growth difference between the eastern region and the central and western regions. In addition to the capital factor, labor factors also have a large gap between the eastern and western regions. Based on the fact that China is still in a labor-intensive and capital-intensive industrial development pattern, the labor factor in the eastern region is also important for economic growth in the region. driving force. Furthermore, the technical factor is also the most important influencing factor. The eastern region has great advantages in this influencing factor. The eastern region has gathered more and more technologies based on its superior geographical position and good development foundation. The accumulation of factors and technical factors is becoming an important factor in the economic growth of the eastern and western regions. It is precisely because of the important role of technological factors in economic growth. The eastern and western regions have paid more and more attention to this key factor in economic development.

Institutional factors are also important factors influencing regional economic growth differences, and to a certain extent, the regional economic growth is increasingly different. Since the eastern region of China is at the forefront of national reform and opening up, it is at the forefront of the country in terms of marketization, economic system reform, property rights system reform, and opening up. The majority of institutional factors have made this region More institutional environment and policy advantages, this advantage can make the eastern region have more contributions to economic growth, and become an important factor influencing the economic growth difference between the eastern and western regions. It is precisely because the central and western regions are significantly weaker than the eastern region in terms of institutional factors and technical factors, indicating that the central region and the western region lag behind the eastern region in terms of technological innovation and research and development capabilities, while at the 
same time opening up and market development. The degree lags behind the eastern region. The differences in institutional factors and technical factors also indicate that there is no effective communication channel between different regions. It is difficult to effectively guarantee the transmission of various influencing factors between regions. communication.

\section{Conclusion}

The balanced development strategy of the regional economy is not only impossible to achieve the goal of regional common prosperity because of the implementation of the planned spatial structure. On the contrary, it also makes all regions fall into the situation of common poverty, which is an unsuccessful strategy. The regional economic tilt development strategy is shaped by the dual structure of market space and as the basis for its implementation. It is not only impossible to achieve the goal of regional common prosperity, but it has caused regional polarization and is therefore an unsuccessful strategy. The Western Development Strategy is the best choice for China's regional economic development strategy because it builds a market structure and uses it as a basis for implementation. It can fully achieve the goal of regional common prosperity.

\section{References}

[1] Wang Liangjian, Guo Qi, Et Al. An Empirical Analysis of the Differences in Economic Development Levels in The Yangtze River Basin[J]. Geography And Geo-Information Science,2005,21(2):66-69.

[2] Liu Wei. Analysis of Regional Economic Differences in The Yangtze River Economic Belt[J]. Yangtze River Basin Resources and Environment, 2006, 15(2): 131-135.

[3] Zeng Guang, Zhou Weilin. An Empirical Analysis of the Differences in Economic Growth in The Yangtze River Delta[J]. Zhejiang Social Sciences,2006,(6):31-39.

[4] Yang Shangguang, Wu Baijun. Regional Economic Development and Spatial Pattern Evolution_-An Empirical Analysis of Economic Growth and Spatial Difference Patterns in The Yangtze River Delta[J]. World Economic Papers,2007,(1):36-47.

[5] Cheng Yuhong. Analysis of Regional Differences in The Economic Circle of the Pan-Pearl River Delta[J]. Academic Research,2005, (3):35-39. 